\section{Determinants of perioperative morbid- ity and mortality after completion pneumonectomy}

\section{To the Editor:}

I read with interest the article by Fujimoto and associates on completion pneumonectomy. ${ }^{1}$ Although the authors obtained a better result than that of some previous reports, the postoperative mortality rate, $7.6 \%$, is still unacceptably high. To my knowledge, perioperative morbidity and mortality differ markedly among experienced surgeons. The mortality may be as high as $30 \%$ or as low as $2 \%$, but the reason for the divergent results has not been established.

I think that the high perioperative morbidity and mortality are related to hemodilution. Hemodilution will increase the production of lymphatic fluid in the heart and lungs. ${ }^{2}$ The increased amount of lymphatic fluid cannot immediately drain through cardiopulmonary lymph ducts because of strong resistance in the mediastinal lymphatic system. ${ }^{3}$ Thus, storage of excess lymphatic fluid in the heart and lungs may harm these organs. ${ }^{4,5}$

Hemodilution during the perioperative period is usually caused by large volume bleeding or excessive water input. I agree that completion pneumonectomy should be done by skilled thoracic surgeons to avoid major blood loss. In addition, strict control of water input is also important. Limitation of water may decrease the production of lymphatic fluid in the heart and lung.

Yingiie Cui, $M D$

Department of Thoracic Surgery First Hospital describing any conflicts of interest related to the contents of the letter

Letters commenting on an article published in the JTCVS will be considered if they are received withın 6 weeks of the time the article was published. Authors of the article being commented on will be given an opportunity to offer a timely response ( 2 weeks) to the letter. Authors of letters will be notified that the letter has been received. Unpublished letters cannot be returned.

Beijing 100034, The People's Republic of China

\section{References}

1. Fujimoto T, Zaboura G, Fechner S, Hillejan L, Schroder T, Marra A, et al. Completion pneumonectomy: indications, complications, and results. $J$ Thorac Cardiovasc Surg. 2001;121:484-90.

2. Drinker CK, Warren MF, Maurer FW, Mccarell JD. The flow, pressure and composition of cardiac lymph. Am J Physiol. 1940;130:43-55.

3. Drake RE, Allen SJ, Williams JP, Laine GA,
Gabel JC. Lymph flow from edematous dog lungs. J Appl Physiol. 1987;62:2416-20.

4. Cui Y. Pulmonary hemodynamic effects resulting from mediastinal lymphatic obstruction in anesthetized rabbits. Med Sci Res. 1999;27:345-8.

5. Cui Y, Urschel JD, Petrelli NJ. The effect of cardiopulmonary lymphatic obstruction on heart and lung function. Thorac Cardiovasc Surg. 2001;49:35-40.

12/8/117619

doi:10.1067/mtc.2001.117619

\section{Reply to the Editor:}

We appreciate the insightful comments by Y. Cui, MD, regarding our manuscript on completion pneumonectomy. As he pointed out, patients who underwent this procedure are especially prone to hemodilution because of the excessive loss of blood and the possibility of excessive fluid overload.

Postpneumonectomy pulmonary edema is one of the most dangerous complications, with its mortality rate being $80 \%$ to $100 \% .1$ Hemodilution, fluid overload, interruption of pulmonary and mediastinal lymphatic drainage, increased vascular permeability, and hyperinflation of the preserved lung are the possible causes of this lethal complication. Physicians should take special care to exclude all these factors, keeping the patient dry after the operation and doing adequate pleural drainage to avoid the mediastinal shift.

Completion pneumonectomy is still a challenging procedure, despite these efforts to decrease morbidity and mortality. Mortality is especially high in patients with early complications of the initial procedure, as shown in our report. Nonetheless, something must be done for patients with otherwise poor prognoses.

Toshio Fujimoto, $M D$

Georgios Stamatis, MD
Surgery and Endoscopy Ruhrlandklinik

Tuschener Weg 40 45239 Essen, Germany

\section{Reference}

1. Deslauriers J, Aucoin A, Gregoire J. Postpneumonectomy edema. Chest Surg Clin North Am. 1999;9:565-86. 